\title{
Evolução histórica da configuração da equipe de enfermagem em um hospital militar
}

\author{
Historical evolution of configuration of the nursing team in a military hospital
}

Raquel Castanheira Bittencourt ${ }^{1}$, Tânia Cristina Franco Santos ${ }^{1}$, Marcleyde Silva de Azevedo Abreu ${ }^{1}$, Antonio José de Almeida Filho ${ }^{1}$, Maria Angélica de Almeida Peres ${ }^{1}$, Pacita Geovana Gama de Sousa Aperibense ${ }^{1}$

Objetivo: analisar a evolução histórica da configuração da equipe de enfermagem em um hospital militar. Métodos: estudo histórico-social. Fontes históricas: documentos escritos e depoimentos orais cedidos por cinco enfermeiras militares. Os dados coletados foram analisados em conformidade com o método histórico, após organização e classificação. Resultados: na chegada dos oficiais enfermeiros ao Hospital Central da Polícia Militar, a equipe de enfermeiros estava reduzida a quatro enfermeiros civis e à enfermeira-chefe. Contava também com cento e setenta sargentos e cabos de saúde e trezentos e quatro funcionários civis (técnicos e auxiliares de enfermagem). 0 cuidado de enfermagem era majoritariamente realizado por profissionais de nível médio que já pertenciam à corporação. Conclusão: os oficiais enfermeiros enfrentaram sobrecarga de trabalho, além das dificuldades com "os praças" (militares das categorias inferiores), no tocante ao acatamento da hierarquia, ocorrendo alguns embates, ensejados por disputas de poder, em um espaço misógino.

Descritores: Enfermagem; História da Enfermagem; Enfermagem Militar.

Objective: to analyze the historical evolution of configuration of the nursing team in a military hospital. Methods: a social-historical study. Historical sources: Written documents and oral statements given by five military nurses. The collected data were analyzed according to the historical method, after organization and classification. Results: when nurse officers arrive to the Military Police Central Hospital, the team of nurses counted with four civilian nurses and the chief nurse. It had 170 health sergeants and soldiers and 304 civil servants (nursing technicians and auxiliaries). Medium-level professionals who already belonged to the corporation mostly performed nursing care. Conclusion: the nurse officers faced work overload, in addition to the difficulties with the military staff of lower categories, regarding the compliance of the hierarchy that caused some conflicts, because of power disputes, in a misogynist environment.

Descriptors: Nursing; History of Nursing; Military Nursing.

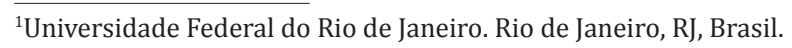




\section{Introdução}

0 presente estudo tem como objeto a configuração da equipe de enfermagem do Hospital Central da Polícia Militar do Estado do Rio de Janeiro em período anterior à chegada da primeira turma de oficiais enfermeiros. 0 recorte temporal refere-se ao ano de 1995 por este ser o período em que a primeira turma veio a ingressar primeiramente como estagiários do Curso de Formação de Oficiais e, posteriormente, como os primeiros oficiais enfermeiros da corporação.

O contexto histórico é o do Brasil e do estado do Rio de Janeiro que, no início dos anos 1990, deparava-se com aumento da criminalidade e da violência urbana. Esse quadro derivou da união de diversos fatores geográficos, sociais e políticos. 0 estado contava com um total estimado de 5.336.179 habitantes, resultado do aumento da população interna e da absorção de uma grande massa populacional envolvida no fenômeno de êxodo rural que ocorria no Brasil, à época ${ }^{(1)}$.

Dados apontam que essa elevação da população urbana, no Rio de Janeiro, em comunhão com o fato dessa cidade ser marcada por significativos contrastes econômicos e sociais, levou ao aumento dos índices de violência. A urbanização agravou problemas de transporte, saneamento básico e poluição do ar, tornando as grandes cidades, como o Rio de Janeiro, vulneráveis às questões de segurança e criminalidade. Notoriamente, a Polícia Militar do Estado sofria diretamente a influência desse panorama social, o que pode ser comprovado pela elevação substancial no número de atendimentos hospitalares da corporação devido não só ao crescimento das necessidades de seus membros, como também ao aumento do efetivo da força enquanto resposta à crise urbana instaurada ${ }^{(1)}$.

Vale ressaltar que os atendimentos em saúde na Polícia Militar do Estado do Rio de Janeiro existem desde o início da corporação, ano de 1809. Os primeiros cargos a serem criados foram os de cirurgião-mor e cirurgião adjuvante ${ }^{(2)}$; posteriormente, foram sendo criados novos cargos, como de odontólogo, por exem- plo, além da ampliação dos cargos de medicina com o aumento das especialidades. Ao longo dos anos, o cuidado de enfermagem foi sendo prestado por funcionários de nível médio, civis e militares.

Com o aumento do efetivo da força ${ }^{(2)}$, na década de 1980, como resposta à crise de segurança pública pela qual o estado passava e em virtude das exigências legais para o exercício da enfermagem, tornou-se necessário admitir funcionários civis para o cargo de enfermeiros. Inicialmente, os enfermeiros civis eram deslocados da Secretaria Estadual de Saúde para trabalhar no Hospital Central da Polícia Militar do Estado do Rio de Janeiro; em seguida, iniciou-se o sistema de contratos renováveis que poderiam ser rompidos por ambas as partes e não se configuravam como vínculo vitalício com a corporação. Tal sistema perdurou até 1995, encerrando-se pouco tempo após a chegada da turma pioneira de enfermeiros oficiais.

Em 1995, a equipe de enfermagem do hospital central era gerenciada por um enfermeiro civil que contava com um diminuto quadro de enfermeiros civis supervisores e um quadro de funcionários de nível médio, composto por civis e militares. À época, o referido Hospital, então com 52 anos de existência, localizado no bairro Estácio, no Rio de Janeiro, tinha capacidade para 220 leitos de internação( ${ }^{(2)}$.

O Hospital comportava uma sala de emergência, com dois leitos para grandes emergências e oito leitos de repouso. Havia também dois centros cirúrgicos, um com quatro salas cirúrgicas em funcionamento para as diversas especialidades e outro para procedimentos ortopédicos. A Unidade de Terapia Intensiva comportava sete leitos e outra unidade intensiva destinada a pacientes cardíacos. Havia ainda clínica cirúrgica, clínica médica, urologia, cardiologia e pneumologia, pediatria, maternidade e central de esterilização, bem como todos os serviços de infraestrutura, como lavanderia, rouparia, cozinha, serviços administrativos diversos, inclusive uma sala destinada à chefia de enfermagem, a qual se localizava no corredor principal de entrada do hospital no andar térreo ${ }^{(2)}$.

Nota-se, portanto, a dificuldade relacionada 
aos recursos humanos de profissionais enfermeiros para a prestação de um serviço de qualidade conforme previsto à época para o campo da saúde. Essa insuficiência de pessoal de enfermagem de nível superior foi ratificada, uma vez que a mesma veio a gerar a necessidade da abertura do concurso de seleção de oficiais enfermeiros por meio da criação do Quadro de Oficiais Enfermeiros dentro do Quadro de Oficiais de Saúde.

A relevância deste estudo em relação aos já publicados sobre a temática se evidencia pelo avanço da discussão sobre a inserção do enfermeiro nos espaços militares, como oficial, cuja aquisição do capital militar funciona como requisito indispensável para a entrada e permanência nesses espaços, tradicionalmente consagrados aos homens, o que se coaduna com a trajetória conflituosa da inserção da mulher no universo do trabalho ${ }^{(3)}$. Isso porque os efeitos históricos das relações assimétricas entre homens e mulheres resultaram na inserção das enfermeiras sistematicamente demarcada por questões de gênero, no cenário militar $^{(4-5)}$. Por outro lado, no que tange aos estudos sobre a história da profissão, compreender experiências passadas também pode se revelar como uma oportunidade de refletir o presente.

A justificativa do estudo é a necessidade de registrar o desenvolvimento profissional da enfermagem militar no Brasil, um campo de atuação de visibilidade no mercado de trabalho para a profissão nos dias atuais. Além disso, existem lacunas do conhecimento quanto à trajetória da profissão, em especial, no cenário militar.

Nesse contexto, objetivou-se analisar a evolução histórica da configuração da equipe de enfermagem em um hospital militar.

\section{Métodos}

Estudo histórico, o qual se caracteriza pela busca das evidências por meio da leitura das fontes históricas diretas e indiretas, de modo a possibilitar a construção de uma versão histórica consistente e eru- dita, balizada pelo olhar crítico do passado(6). Os documentos escritos e orais compuseram as fontes diretas do estudo. A técnica para a obtenção de documentos orais foi a História Oral Temática que, ao ser confrontada com outras fontes, torna mais rico seu potencial como fonte de pesquisa ${ }^{(7)}$.

Os documentos escritos que integraram o corpus documental do estudo foram o Livro de Ordens e Ocorrências, o Manual de Rotinas e o Manual de Técnicas, utilizados no período em estudo. 0 acesso aos documentos escritos foi viabilizado pela Carta de Anuência assinada pelo diretor geral do hospital.

Realizaram-se entrevistas com cinco enfermeiros que fizeram parte da primeira turma de oficiais e que foram alocadas no Hospital durante todo o ano de 1995. Por se tratar de pesquisa histórica, as entrevistas realizadas deram conta de atender aos objetivos do estudo, visto que na história oral até mesmo uma única entrevista pode ser relevante, desde que seja suficientemente significativa para viabilizar certo grau de generalização dos resultados do estudo ${ }^{(7-8)}$. Após os participantes declararem que não estavam com dúvidas sobre o desenvolvimento do estudo e respectivos objetivos, firmaram o Termo de Consentimento Livre e Esclarecido, em duas vias. As entrevistas, com duração média de 50 minutos, foram gravadas por meio digital e, posteriormente, transcritas e validadas pelos participantes, mediante leitura e autorização escrita pelos mesmos. Excluíram-se da pesquisa os oficiais enfermeiros que não fizeram parte da primeira turma ou que não foram alocados no Hospital Central da Polícia Militar do Estado do Rio de Janeiro.

As entrevistas ocorreram no mês de dezembro de 2018 e janeiro de 2019. 0 local das entrevistas foi definido pelas participantes, ocorrendo no próprio ambiente de trabalho. As entrevistas foram norteadas por um roteiro semiestruturado com oito perguntas abertas sobre o tema em questão. A identidade dos participantes foi preservada e se utilizou uma codificação para identificação (Ent01, Ent02, Ent03, Ent04 e Ent05).

Para análise do corpus documental, adotaram- 
-se procedimentos ativos de interrogação dos documentos, de modo a evidenciar o fenômeno histórico consoante com uma postura crítica. A confiabilidade dos resultados foi assegurada pela justaposição do conjunto documental, e não os documentos de forma isolada.

Os dados foram analisados com base em fontes indiretas, as quais foram constituídas de livros e artigos sobre o tema, com ênfase nos estudos sobre enfermagem militar; e artigos que adotavam conceitos próprios à metodologia histórica ${ }^{(7-8)}$. Em conformidade com o método histórico, os achados foram organizados após o processo de classificação e organização.

0 presente estudo advém do projeto aprovado pelo Comitê de Ética em Pesquisa com parecer $\mathrm{n}^{\mathrm{o}}$ 2.930.713/18 e seguiu as diretrizes éticas em consonância com as Resoluções 466/12 e 510/16, ambas do Conselho Nacional de Saúde.

\section{Resultados}

Em 1995, a equipe de enfermagem do hospital central se mostrava heterogênea, sendo composta por enfermeiros civis e cabos, sargentos e subtenentes "Enfermeiros". A equipe de enfermagem do hospital era gerenciada por um enfermeiro civil e seu quadro de pessoal contava com treze enfermeiros civis em exercício nos diversos setores; cento e setenta sargentos e cabos de saúde, denominados em suas placas de identificação como sargentos e cabos enfermeiros, apesar de terem a formação de nível médio; e trezentos e quatro funcionários civis (técnicos e auxiliares de enfermagem).

0 cuidado de enfermagem era majoritariamente realizado por profissionais de nível médio que já pertenciam à corporação. Os policiais que possuíam formação de técnicos, auxiliares e atendentes de enfermagem eram remanejados para cumprirem essas funções dentro do hospital, mesmo que tivessem ingressado na Polícia Militar por meio do concurso para guardas combatentes. Não raro, eles exerciam a função de enfermeiros mesmo não tendo a formação necessária para tal. Alguns até mesmo possuíam a graduação em enfermagem, entretanto não haviam ingressado na força por meio de testes que validassem esse conhecimento. Mesmo assim, esses praças, militares pertencentes às categorias inferiores na hierarquia militar, representados por soldados ou cabos, eram identificados como Cabos, Sargentos e Subtenentes "Enfermeiros" e tinham essa denominação registrada em suas insígnias, isto é, nas placas de identificação que assim os apresentavam.

Excertos das entrevistas evidenciam a perplexidade das oficiais enfermeiras no tocante à sobrecarga de trabalho que era imposta aos poucos funcionários que o Hospital dispunha para realizar os atendimentos: Eu não sei como eles [a equipe de saúde] conseguiam dar conta... era algo surreal que eu nunca vi na minha vida... mais de duzentos leitos, todos ocupados, e só elas ali, para um hospital inteiro... gente de todas as patentes, do soldado ao coronel, com suas necessidades, reivindicações... e ainda tinham as famílias, no nosso trabalho a gente não pode esquecer das famílias...(Ent03). A supervisão de enfermagem dos setores era realizada por enfermeiros civis e devido à insuficiência quantitativa, os subtenentes e sargentos também supervisionavam... (Ent01).

No recorte deste estudo, a composição da equipe de saúde militar do hospital central era formada por médicos, dentistas, farmacêuticos e sargentos e cabos "enfermeiros". A civil era constituída de médicos, enfermeiros, técnicos de enfermagem, auxiliares de enfermagem e funcionários administrativos. Como supracitado, a equipe de enfermagem contava apenas com treze funcionários no cargo de enfermeiros, que acabavam por realizar ações apenas de supervisão, não conseguindo dar conta das demais demandas da assistência. Os enfermeiros civis apenas chefiavam... eles lideravam, mas lá da chefia... se precisasse de algo importante tinha que entrar em contato com a supervisão de enfermagem, se fosse algo menor, que desse para contornar, era com a gente mesmo... lembro de receber esse recado de cara... lá debaixo, eles apenas supervisionavam (Ent03).

Evidenciou-se também que os praças militares apresentavam em sua identificação profissional a denominação de enfermeiro, portanto, mesmo sem sê-lo, angariavam poder no espaço de atuação profissional. Sobre isso, assim se referiu uma participante do 
estudo: No meu setor, a maioria da equipe de enfermagem era de muitos técnicos de enfermagem civis, pelo menos no setor em que eu fiquei, mais da metade da equipe em que eu fiquei era de civis. Eu tinha alguns militares, na verdade um militar só e, em alguns plantões, dois militares como plantonistas e eles se intitulavam assim, como os chefes, os líderes da equipe. Então era Cabo Enfermeiro... Sargento Enfermeiro, apesar de não ter a formação. Que eu saiba, em todo o hospital, dois possuíam até o curso superior, mas os demais não tinham a formação, mas eram intitulados como enfermeiros e eles definiam, junto com o grupo dos civis, o que tinha que ser feito. Não tinha enfermeiro civil no meu setor (Ent02).

Assim, o pessoal de nível médio, tanto militar quanto civil, realizava o cuidado de enfermagem e, até mesmo, procedimentos que cabiam aos enfermeiros. Quando algum procedimento era mais complexo ou surgia alguma necessidade no campo, a chefia de enfermagem era acionada. Ademais, no dia a dia, as questões referentes ao cuidado eram resolvidas pelos técnicos e auxiliares.

Vale ressaltar que a divulgação da criação do Quadro de Oficiais de Enfermagem, por si só, já ensejou alterações dentro da corporação. Diante da iminência de sua substituição nos cargos de chefia ou na supervisão da equipe de enfermagem, gradativamente, o número de enfermeiros civis foi diminuindo, o que se deu tanto pela não renovação dos contratos anuais vencidos como pelo desligamento por parte dos próprios funcionários. Além disso, a diminuição do número de enfermeiros também se deu em decorrência da aprovação no concurso para oficiais enfermeiros, pois quatro foram aprovados, tendo sido afastados temporariamente para realizar o curso obrigatório de formação de oficiais. Do quadro de praças, quatro também foram aprovados para o realizar o referido curso, pois possuíam formação específica em Graduação em Enfermagem.

Observou-se também o aumento do absenteísmo dentre a equipe civil, evidenciada nos Livros de Ordens e Ocorrências. As consultas nesses livros retratam, de maio a novembro de 1994 (fase anterior à chegada dos oficiais enfermeiros), que a média de faltas era de três faltas/dia. No período de junho a setembro de 1995, após a assunção dos oficiais enfer- meiros, a média evoluiu para sete faltas/dia.

A iminência da chegada de enfermeiros com patente de oficial em um hospital militar, certamente, ensejou nos enfermeiros civis o entendimento de que os oficiais enfermeiros assumiriam posições de poder e prestígio, em face do peso do capital militar por eles angariado no estágio de formação de oficiais. Sendo assim, essa condição assimétrica entre profissionais pode ter suscitado desmotivação e contribuído para o aumento do absenteísmo.

A brusca redução ocorrida em uma equipe já tão restrita fez com que a atuação da equipe de enfermagem civil se concentrasse cada vez mais na supervisão e chefia de enfermagem, abrindo ainda mais espaço para a ocupação de posições de liderança e comando dos cabos e sargentos 'enfermeiros'. Conforme consta no Livro de Ordens e Ocorrências, 1995, dos treze enfermeiros civis, quatro foram aprovados no concurso para oficiais enfermeiros, dois não obtiveram a renovação do seu contrato anual e três pediram desligamento das funções por motivos pessoais. Assim, quando os oficiais enfermeiros efetivamente começaram a ocupar os espaços do hospital, a equipe de enfermeiros estava reduzida a quatro enfermeiros civis e à enfermeira-chefe.

\section{Discussão}

Como limitação do estudo, podem ser pontuadas as percepções dos autores, que escrevem de um lugar social, ou seja, a partir de um ponto de vista que é atravessado por subjetividades. Destarte, a tarefa de produzir um estudo histórico não prescinde de múltiplas influências. Ainda assim, recomenda-se a realização de mais estudos históricos sobre o desenvolvimento da enfermagem nos espaços militares, visto que só o conhecimento da história possibilita a compreensão de como a enfermagem tem se construído e avançado ao longo do tempo. Sendo assim, a aplicabilidade prática dos resultados do presente estudo contribui para o desenvolvimento de um compromisso com a profissão.

Os achados evidenciaram que os recursos hu- 
manos eram insuficientes para atender às demandas de assistência de enfermagem de um grande hospital como o Hospital Central da Polícia Militar do Estado do Rio de Janeiro. A intensa rotina de atendimentos do hospital correspondia ao ritmo de trabalho dos policias que só aumentava com o avanço da criminalidade e da violência urbana. Tal quadro social aumentava a busca pelos serviços de saúde por duas vertentes: a primeira, de caráter imediatista, diz respeito a maiores e mais graves necessidades dos policias relacionadas à prática profissional, isto é, ao ofício da profissão e os danos à saúde por ele provocados, como desgastes físico e psicológico e demandas ocasionadas pelos envolvimentos em confrontos militares; a segunda, posteriormente apresentada, correlaciona-se com o aumento do número de atendimentos, já que a força estava em crescente expansão devido aos incrementos, já citados, da corporação que se expandia como resposta à crise urbana.

A essa equação que inevitavelmente traduz uma estrutura sobrecarregada, soma-se ainda mais um fator determinante. Em 1983, pela Portaria 0062/83 da Polícia Militar do Estado do Rio de Janeiro, os dependentes dos militares, ativos, da reserva e da reforma, passam a ter direitos de utilizar os serviços de saúde da corporação. Cabe lembrar que apenas em 1990 o Sistema Único de Saúde brasileiro se estrutura como um sistema único e universal de atendimento gratuito à população e que grande parte da mesma não possuía meios financeiros de arcar com gastos com planos de saúde ou serviços particulares. Sendo assim, a possibilidade de utilizar os serviços de saúde da corporação militar surgiu como um bálsamo para essas pessoas que, agora, dispunham de assistência em saúde especializada, qualificada e gratuita. Tal medida contribuiu para ampliar o quantitativo de atendimentos nos serviços de saúde, tornando mais visível a deficiência quantitativa de membros da equipe de saúde, em especial enfermeiros e pessoal de nível médio(2).

A deficiência quantitativa de recursos humanos para satisfazer as necessidades do hospital que a cada dia cresciam mais foi apontada nos extratos das entrevistas. Para atendimento emergencial, o Hospital rece- bia diariamente muitos policiais feridos gravemente em confrontos e operações realizadas no desempenho de suas funções. Nessa época, a cidade do Rio de Janeiro vivenciava altos índices de criminalidade, o que ensejava a necessidade de muitos atendimentos ${ }^{(2)}$. Esse aumento da demanda de assistência hospitalar e ambulatorial também encontrava justificativa na ampliação do quadro de policiais e dependentes que também tinham direito à assistência nas unidades citadas da Polícia Militar.

A supervisão de enfermagem dos setores era realizada por enfermeiros civis e, devido à insuficiência quantitativa, os subtenentes e sargentos enfermeiros também participavam da supervisão. Esses profissionais tinham autoridade para relatar ocorrências no Livro de Supervisão, tais como pacientes graves; cirurgias; transferências; óbitos; queixas; remanejamentos, faltas e atrasos de funcionários ${ }^{(2)}$.

A assistência de Enfermagem ficava a cargo, majoritariamente, do pessoal de nível médio, cabendo ao enfermeiro a chefia dos setores e a execução, quando possível, de procedimentos de enfermagem de maior complexidade, além da supervisão geral da assistência de enfermagem ${ }^{(2)}$. Nesse contexto, os profissionais de enfermagem podem apresentar sinais de desgaste físico e emocional, advindos de níveis de sobrecarga de trabalho, ambiente laboral inapropriado e desagrado com a profissão ${ }^{(9-10)}$, resultado em aumento do número de faltas. Ademais, também causava inquietações a implementação do cuidado por profissionais de nível médio, bem como os militares subalternos titulados enfermeiros. Essas situações conferiam invisibilidade à presença e importância do enfermeiro na equipe de saúde, podendo comprometer a qualidade da assistência, uma vez que os ambientes laborais inadequados influenciam na qualidade do cuidado(11-12).

Sendo assim, o pessoal de nível médio, civil e, sobretudo, militar eram as linhas de frente do cuidado de enfermagem, prestando a assistência direta aos enfermos à beira do leito. Já a diminuta equipe de quatro enfermeiros civis concentrava-se nas atividades de chefia de enfermagem e supervisão, sendo acionados no andar somente quando em extrema necessidade e 
não participando do cuidado direto aos pacientes em razão do seu reduzido quantitativo de pessoal. Este era o quadro de atuação da equipe de enfermagem em 1995, quando a turma pioneira assumiu os cargos que lhes eram assegurados no hospital da corporação, após a conclusão do curso de oficiais.

Como visto nos excertos das entrevistas, os oficiais enfermeiros se depararam com a evasão do já diminuto quadro de enfermeiros em virtude de situações desfavoráveis a eles em um hospital militar. Nesse mister, em curto espaço de tempo, a inserção nesse cenário exigiu dos oficiais enfermeiros, em curto espaço de tempo, conhecimento e liderança, de modo a ocupar posições de poder no espaço militar, representado pelo hospital onde atuariam. Isso porque, historicamente, as posições de comando por enfermeiros, em geral, ainda são reduzidas e não é diferente nas instituições militares ${ }^{(13-14)}$.

Vale ressaltar que a notícia da chegada dos oficiais enfermeiros, por si só, já ensejou mudanças dentro da equipe de enfermagem. Notaram-se desligamentos de enfermeiros civis, bem como o aumento do absenteísmo desses agentes. A percepção da chegada de novos agentes que viriam assumir posições de poder no espaço hospitalar pode ter sido essencial na origem dessas situações, tendo em vista que a superioridade do profissional militar em relação ao civil seja tida como algo natural no campo militar ${ }^{(3)}$. Além disso, o fim dos contratos dos civis, sua não renovação e aprovação de parte (quatro) da equipe no concurso para oficial fizeram com que o restante da equipe de enfermeiros civis, apenas quatro, se concentrasse ainda mais nas atividades de supervisão.

Assim, a inserção dos oficias enfermeiros recém-ingressos no campo gerou uma reordenação da equipe de enfermagem, já que os cargos de chefia passaram para os oficiais enfermeiros, uma vez que, pela lógica militar, a antiguidade é mandatória para a ocupação dos cargos de chefia ${ }^{(3)}$. Tal reordenação foi recebida de maneira distinta pelos enfermeiros civis e os militares: para os enfermeiros civis, a recepção foi extremamente positiva, já que a chegada dos oficiais enfermeiros daria visibilidade à importância do enfer- meiro no hospital; para os praças, houve dificuldades no tocante ao acatamento da hierarquia, pois ocorria inúmeros embates, ensejados por disputas de poder.

Os embates eram a forma que o grupo de praças de saúde encontrava de tentar manter sua posição dominante, ainda que a hierarquia militar apontasse no sentido oposto, apontando para a nítida existência de movimentos heréticos nesse campo. 0 fato da enfermagem de nível superior compor um grupo majoritariamente feminino pode ter sido determinante para a ocorrência de tão veemente resistência por parte dos praças, grupo majoritariamente masculino, visto que entraves são mantidos em relação à profissão - por esse mesmo motivo - até os dias de hoje devido à manutenção de certos limites à profissão no campo militar, como o difícil acesso à posição máxima na carreira do enfermeiro ${ }^{(2)}$. A violência simbólica se materializava, entre outras, pela resistência às ordens desferidas pela turma pioneira, até mesmo boicotes foram utilizados pelos praças na tentativa de manutenção do poder no espaço hospitalar. Assim, o estudo permitiu identificar que tanto as enfermeiras civis como os praças empreenderam o que se chama de estratégias defensivas para enfrentar as novas exigências laborais ${ }^{(15)}$, as quais incluíam o distanciamento através do absenteísmo ou enfrentamentos por meio da resistência à nova ordem no espaço laboral.

\section{Conclusão}

Depreende-se que a equipe de enfermagem do hospital central, às vésperas da entrada da turma pioneira de oficiais enfermeiros, em 1995, estava sobrecarregada de atividades cujas dificuldades em executá-las a contento poderiam prejudicar a assistência aos enfermos, bem como a visibilidade da importância do enfermeiro, uma vez que as atividades assistenciais e até mesmo a supervisão eram realizadas por militares designados enfermeiros, não qualificados, para o exercício de tais atividades. Essa é a situação encontrada pelos oficiais enfermeiros ao serem inseridos no referido Hospital. 


\section{Agradecimentos}

À Coordenação de Aperfeiçoamento de Pessoal de Nível Superior, processo: 88882.183348/2018-01, e ao Conselho Nacional de Desenvolvimento Científico e Tecnológico, processo: 307523/2018-7.

\section{Colaborações}

Bittencourt RC contribuiu para análise e interpretação dos dados, redação do artigo e aprovação final da versão a ser publicada. Santos TCF contribuiu para a concepção e projeto e revisão crítica relevante do conteúdo intelectual. Abreu MAS, Almeida Filho AJ, Peres MAA e Aperibense PGGS contribuíram para a revisão crítica relevante do conteúdo intelectual.

\section{Referências}

1. Fausto B. História do Brasil. São Paulo: EDUSP; 2015.

2. Abreu MSA, Haddad VCN, Costa LMC, Teixeira KRB, Peres MAA, Santos TCF. First officer nurses of the Military Police of the State of Rio de Janeiro (1994-1995): incorporation of military habitus. Esc Anna Nery. 2015; 19(4):535-41. doi: http:// dx.doi.org/10.5935/1414-8145.20150071

3. Orichio APC, Peres MAA, Costa LMC, Almeida Filho AJ, Santos TCF. Female nursing officers in the navy: from entry into the military to first promotion. Rev Enferm UERJ. 2016; 24(6):e18117. doi: http:// dx.doi.org/10.12957/reuerj.2016.18117

4. Bernardes MMR, Oliveira AB, Kaminitz S, Gomes AMT, Marques SC, Porto FR. The Brazilian Army nurses' uniforms: visual identity in World War II. Rev Bras Enferm. 2019; 72(1):111-7. doi: http:// dx.doi.org/10.1590/0034-7167-2018-0414

5. Oliveira AB, Bernardes MMR, Kneodler TS, Lourenco MBC. Memories revealed: veteran nurses discourses on their fight for reinstatement in the military field. Texto Contexto Enferm. 2017; 26(3):e2720016. doi: http://dx.doi. org/10.1590/0104-07072017002720016

6. Padilha MICS, Bellaguarda MLR, Nelson S, Maia ARC, Costa R. The use of sources in historical research. Texto Contexto Enferm. 2017; 26(4):e2760017. doi: dx.doi.org/10.1590/010407072017002760017
7. Teodosio SSS, Silva ER, Padilha MI, Mazera MS, Borenstein MS. Oral history and documental investigation as a research itinerary in nursing: a bibliometric study (2000-2014). Esc Anna Nery. 2016; 20(4):e20160087. doi: http://dx.doi. org/10.5935/1414-8145.20160087

8. Gomes SC, Silva JA, Oliveira DR, Machado MFAS, Pinheiro AKB, Quirino GS. The oral history as a method for understanding the Brazilian semi-arid midwives. Texto Contexto Enferm. 2018; 27(3):e2470017. doi: http://dx.doi. org/10.1590/0104-07072018002470017

9. Möller G, Magalhães AMM. Bed baths: nursing staff workload and patient safety. Texto Contexto Enferm. 2015; 24(4):1044-52. doi: http://dx.doi. org/10.1590/0104-0707201500003110014

10. Lopes DMQ, Lunardi Filho WD, Beck CLC, Coelho APF. The workload of the community health agent: research and assistance in the perspective of convergent-care. Texto Contexto Enferm. 2018; 27(4):e3850017. doi: http://dx.doi. org/10.1590/0104-07072018003850017

11. Granero ABJM, Ochoa P. Labor conditions and the meanings of nursing work in Barcelona. Rev LatinoAm Enfermagem. 2018; 26:2947. doi: http:// dx.doi.org/10.1590/1518-8345.2342.2947

12. Aperibense PGGS, Silva CPG, Santos TCF, Almeida FAJ, Nelson S, Peres MAA. The uniform of nursing students: a strategy for the construction of professional identity (1950-1960). Texto Contexto Enferm. 2019; 28:e20170593. doi: http://dx.doi. org/10.1590/1980-265x-tce-2017-0593.

13. Sell CT, Padilha MICS, Peres MAA. Military nurses: roles from 1980 to 1997. Rev Enferm UERJ. 2015; 23(6):741-6. doi: http://dx.doi.org/10.12957/ reuerj.2015.9686

14. Lourenço MBC, Pinto CMI, Silva OCJ, Lourenço LHSC, Paes GO, Oliveira AB. The inclusion of Brazilian flight female nurses in the second world war: challenges and achievements. Esc Anna Nery. 2017; 21(4):e20170008. doi: http://dx.doi. org/10.1590/2177-9465-ean-2017-0008

15. Lamb FA, Beck CLC, Coelho APF, Bublitz S, Aozane F, Freitas P H. Defensive strategies of nursing workers in the pediatric emergency room. Rev Rene. 2017; 18(4):453-60. doi: https://dx.doi. org/10.15253/2175-6783.2017000400005 